\title{
A Enfermagem Oncológica no Enfrentamento da Pandemia de Covid-19: Reflexões e Recomendações para a Prática de Cuidado em Oncologia
}

doi: https://doi.org/10.32635/2176-9745.RBC.2020v66nTemaAtual.1007

\author{
Oncology Nursing in Coping with the COVID-19 Pandemic: Reflections and Recommendations for Oncology Care Practice \\ Enfermería en Oncología para hacer frente a la Pandemia Covid-19: Reflexiones y Recomendaciones para la Práctica de \\ Atención oncológica
}

Raquel de Souza Ramos'

\section{INTRODUÇÃO}

A saúde pública mundial está, diariamente, sendo desafiada por uma doença cuja fisiopatologia ainda é desconhecida e que é objeto de investigação de inúmeros pesquisadores em todo o mundo: a coronavirus disease 2019 (Covid-19). Ela é causada pelo novo tipo de coronavírus (2019-nCoV), da síndrome respiratória aguda grave do coronavírus 2 (severe acute respiratory syndrome coronavirus 2 - Sars-CoV-2) e, em linhas gerais, e como já amplamente apresentado e discutido pela comunidade científica, esse vírus leva ao desenvolvimento de casos de síndromes respiratórias graves, pneumonias, doenças entéricas, hepáticas, neurológicas entre outras manifestaçôes com uma letalidade específica relativamente baixa. Entre as características já identificadas desse vírus estão a estrutura composta por camada lipídica e a alta transmissibilidade, o que alicerça todas as medidas de prevenção e de precaução universal adotadas nas unidades de saúde e na comunidade, principalmente o distanciamento social e a lavagem das mãos ${ }^{1}$. De posse desses apontamentos, o presente estudo objetiva apresentar uma reflexão sobre as práticas de cuidado da enfermagem no contexto da oncologia em tempos do enfrentamento da pandemia da Covid-19 no Brasil.

\section{DESENVOLVIMENTO}

A equipe de enfermagem representa cerca de $50 \%$ da força de trabalho mundial no campo da saúde e são os profissionais que permanecem 24 horas, nos sete dias da semana, ao lado das pessoas que recorrem aos serviços de saúde, desde o nascimento até após o óbito, realizando os cuidados com o corpo post mortem ${ }^{2}$. No Brasil, existem atualmente mais de dois milhóes de profissionais de enfermagem, o que traz à tona um grande desafio para as lideranças de enfermagem, no sentido de preservar e zelar pelo exercício profissional de forma segura conforme as recomendaçóes sanitárias e garantias legais do Código e Ética dos Profissionais de Enfermagem ${ }^{3}$.

Um contexto de pandemia exige mudanças significativas e frequentes nos hábitos de vida e nas rotinas dos profissionais, nos protocolos e fluxos institucionais, o que requer que os profissionais compreendam este momento de crise como oportunidade para elevar a profissão a patamares sociais nunca antes vistos em nosso país e que esse reconhecimento social possa mudar práticas e políticas referentes à enfermagem.

O cotidiano de atuação requer que o profissional revisite suas competências, habilidades e atitudes e as adeque ao momento atual para o desenvolvimento do cuidado, compreendendo que esse cuidado se desenvolve em níveis de complexidade distintos, porém indissociáveis, que transitam desde uma simples ação educativa sobre lavagem das máos até as práticas de cuidado na alta complexidade.

Observa-se um acelerado processo de construção e atualização do conhecimento acerca do assunto, exigindo, dessa forma, que os profissionais que estáo na linha de frente de atendimento estejam atualizados de forma permanente e aptos a desenvolverem uma prática de cuidados que seja segura para o paciente, para si próprio, para os demais membros da equipe que atuam no cenário e para a comunidade por onde esse profissional irá circular após o término de seu turno de trabalho, além de instrumentalizá-lo para o reconhecimento de sinais e sintomas que possam sugerir a infecção pelo coronavírus.

Estudos apontam que o reconhecimento precoce de indivíduos infectados é crucial para que haja sucesso no tratamento e na redução da transmissibilidade. Nesse

${ }^{1}$ Enfermeira. Doutora em Enfermagem pela Universidade do Estado do Rio de Janeiro (Uerj). Instituto Nacional de Câncer José Alencar Gomes da Silva (INCA) Seção de Cirurgia Urológica e Plástica/Área de Ensino de Enfermagem. Hospital Universitário Pedro Ernesto, Coordenadoria de Enfermagem. Presidente da Sociedade Brasileira de Enfermagem Oncológica. Orcid iD: https://orcid.org/0000-0001-7331-9715

Endereço para correspondência: Raquel de Souza Ramos. Praça Cruz Vermelha, 23 - 4º andar - Ala A - Centro. Rio de Janeiro (RJ), Brasil. CEP $20230-130$. E-mail: rramos@inca.gov.br 
sentido, oferecer capacitação periódica para as equipes torna-se imperioso, pois o conhecimento os empodera para tomar decisóes em momentos oportunos e que são decisivos para o desfecho favorável por meio da implementação de intervençôes terapêuticas precoces 4 .

Apesar da gravidade e do foco das açóes das unidades de atendimento de saúde estarem voltadas para contornar a crise instalada pelo coronavírus nos sistemas de saúde mundiais, é irrefutável que as outras doenças continuem afetando os diversos segmentos populacionais, entre elas o câncer, que se apresenta como um grave problema de saúde pública mundial, destacado com uma das quatro principais causas de morte precoce 5 .

A realidade dos sistemas de saúde no mundo revela uma escassez e uma forte tendência de desabastecimento de equipamentos de proteção individual (EPI) no Brasil e em diversos países, em especial das máscaras cirúrgicas N95/PFF2. Os hospitais estão sobrecarregados com o atendimento dos pacientes infectados pelo vírus, portanto, é salutar que as instituiçôes destinadas ao atendimento de pacientes oncológicos sejam mantidas o maior tempo possível livre de pacientes com diagnóstico firmado para a Covid-19. Essas instituiçôes são fundamentais para que o tratamento das pessoas com câncer transcorra de maneira segura e eficaz, principalmente em casos de tumores agressivos.

O crescimento desordenado e rápido das células tumorais que caracterizam o adoecimento por câncer requer intervençóes terapêuticas o mais precoce possível no sentido de controle da doença, redução da ocorrência de metástases locais e a distância, bem como a utilização de métodos terapêuticos que possam trazer menores danos e sequelas para as pessoas com câncer. Destaca-se que os pacientes oncológicos fazem parte do grupo de alto risco para a Covid-19 diante da imunossupressão secundária ao tratamento ou da imunodepressão relacionada ao adoecimento por câncer. Assim, as instituiçôes e pacientes oncológicos são igualmente afetados, exigindo uma nova organizaçáo das práticas de cuidados, bem como o desenvolvimento de habilidades específicas que serão fundamentais para o sucesso do tratamento oncológico ${ }^{6}$.

Nesse contexto, a enfermagem oncológica brasileira está enfrentando grandes desafios, sem precedentes históricos em sua atuação, nos diversos cenários da assistência à saúde, sendo convocada a revisitar a sua prática e a elaborar novas estratégias para minimizar os impactos gerados pela pandemia no atendimento oncológico.

Uma das estratégias amplamente recomendadas pelas autoridades mundiais e pela comunidade científica que se debruça incessantemente sobre a investigação sobre o vírus é o distanciamento social. Essa medida vem se mostrando eficaz para promover o achatamento da curva de transmissibilidade do vírus. Em função da imunossupressão e imunodepressão que os pacientes oncológicos frequentemente apresentam, as orientaçóes de distanciamento social devem ser fortemente recomendadas para esse grupo de pacientes. Todavia, é fundamental que os riscos inerentes às interrupçóes significativas nos cuidados associados aos comportamentos sociais de distanciamento sejam minuciosamente analisados e atenuados. Recomenda-se, portanto, que os pacientes sejam encorajados a náo interromper o tratamento, pois já existem relatos de alguns que optaram por cancelar consultas e procedimentos por receio de serem contaminados pelo vírus. Considerando que o profissional de enfermagem é o que tem maior contato e proximidade com os pacientes no cotidiano de atendimento dos serviços de saúde, a abordagem junto aos pacientes poderá conferir confiança ao paciente e familiar e contribuir para uma maior adesáo ao tratamento proposto.

Para que a manutenção do tratamento náo se torne um risco frente à alta virulência do Sars-CoV-2, recomenda-se que o enfermeiro realize uma avaliaçáo personalizada, que promova orientaçôes pautadas nas recomendaçóes do Ministério da Saúde e dos guidelines internacionais, reforcem exaustivamente as medidas universais básicas de prevenção, como a higiene das mãos, uso de máscaras e não contato com pessoas suspeitas ou diagnosticadas com a doença induzida por esse vírus.

A organização dos espaços e fluxos de atendimento é outra atividade que o enfermeiro pode estar envolvido, principalmente das emergências oncológicas diante da maior possibilidade de contato entre pacientes suspeitos ou com a doença sem diagnóstico ainda firmado em um mesmo espaço de atendimento. Uma recomendaçáo adotada, atualmente, é que o paciente seja acompanhado apenas por uma única pessoa no seu atendimento para minimizar aglomeraçóes. Algumas instituiçôes estáo oferecendo o teleatendimento como estratégia de atendimento e como um canal de comunicação entre os pacientes e a equipe de saúde para evitar idas desnecessárias às instituições, introduzindo uma nova modalidade de atendimento em nossa profissão. É recomendado que, para tal, o profissional tenha a habilidade de comunicação bastante desenvolvida, visando à garantia de compreensão e à apreensão das orientaçóes pelos pacientes e familiares ${ }^{7}$.

Outra frente de atuação da enfermagem oncológica é $o$ atendimento direto aos pacientes durante a internação hospitalar, que talvez se apresente como o cenário mais desafiador para a equipe que atende aos pacientes oncológicos, seja em unidades de terapia intensiva ou em unidades de internaçáo de menor complexidade de cuidado. O tratamento oncológico, por si só, já é permeado 
com uma grande complexidade que exige do profissional, que atua na especialidade, conhecimentos habilidades e atitudes bastante específicas, que são capazes de causar estresse laboral, além de riscos de comprometimento da saúde do trabalhador por exposição a agentes físicos e biológicos, conforme destacados em estudos de grande relevância. Neste momento, mais um elemento, também complexo e ainda desconhecido, é acrescentado ao cotidiano de trabalho dessas pessoas, aumentando ainda mais os riscos de comprometimento da saúde desses trabalhadores ${ }^{8}$.

Em vista disso, é preciso estar atento e ressaltar a síndrome de Burnout, ou síndrome do esgotamento profissional, que pode acometer os profissionais de enfermagem que atuam na oncologia. Tal síndrome é caracterizada por distúrbio emocional evidenciado por sintomas de exaustáo extrema, estresse e esgotamento físico, decorrentes de condições laborais desgastantes que demandam competitividade ou grande carga de responsabilidade. Considerando as condiçóes extremas de pressão emocional, física e mental, resultantes dessa pandemia, é possível inferir que existe grande possibilidade de desenvolvimento da síndrome de Burnout pela força de trabalho, o que representa mais um ponto de preocupação com a saúde dos profissionais de saúde ${ }^{8}$.

A pandemia de Covid-19 exige que o enfermeiro tenha, além da habilidade técnica e conhecimento específico no campo da oncologia, liderança, constante atualização dos conhecimentos sobre os protocolos dos órgãos governamentais e das diretrizes internacionais sobre o tratamento da doença e sobre as medidas de proteçáo dos profissionais, e dedicação, determinação, senso de coletividade e de responsabilidade social, assumidos ao se tornar um profissional da área da enfermagem.

Ao enfermeiro gestor, cabe desempenhar com responsabilidade a liderança técnica que seja capaz de atender às diversas demandas advindas da crise com o envolvimento dos diversos segmentos da instituição. É fundamental o desenvolvimento de protocolos que sejam atualizados de acordo com as mudanças das diretrizes e que estes sejam amplamente divulgados a todos os colaboradores da instituição. Realizar atividades de capacitação das equipes exaustivamente, principalmente no que tange aos procedimentos de paramentaçáo e desparamentação para garantir que esses profissionais não se contaminem, evitando, dessa forma, uma reduçáo do contingente no front de atendimento, é outra atribuição fundamental das lideranças do segmento.

Os profissionais que estão atuando na linha de frente não estão imunes a contrair a doença e um alto número de absenteísmo poderá afetar o atendimento das pessoas com câncer, conforme já reportado por estudo recentemente publicado na Lancet-Oncology?.
Aos gestores, cabe também planejar estratégias de acompanhamento e monitoramento dos profissionais afastados pela Covid-19, e definir a forma mais segura de retorno dos profissionais ao final da quarentena, gerar indicadores de qualidade para orientar as mudanças de fluxo dos pacientes, acompanhantes e profissionais, bem como garantir a governabilidade e economicidade dos insumos fundamentais ao atendimento.

O suprimento de EPI para os profissionais e de insumos específicos para o atendimento dos pacientes oncológicos, sejam eles acometidos ou não pela Covid-19, tem sido outro ponto crítico e nevrálgico no cenário mundial. Dessa forma, é fundamental o gerenciamento adequado e responsável, e alocação apropriada desses recursos limitados de assistência neste período de crise global nos serviços de saúde. O treinamento dos profissionais certamente é decisivo para que haja o uso racional e adequado dos recursos disponíveis, evitando o total desabastecimento que levará a consequências desastrosas nos atendimentos dos serviços de saúde.

Outro aspecto que merece atenção é o elemento emocional das equipes de atendimento. Os profissionais estão ansiosos nesse ambiente frente à possibilidade iminente de exposição ao vírus e ao adoecimento, que pode ter um curso bastante desfavorável, e ainda precisam levar tranquilidade para os pacientes que já lidam com uma doença com risco de vida e, ao mesmo tempo, enfrentam essa terrível pandemia. A limitação de visitas e acompanhantes é outra medida que se faz necessária e, nesta ocasiáo, promove um maior afastamento dos pacientes de seus familiares ${ }^{7}$. Em determinados momentos, poderá ser necessária a tomada de decisōes importantes sobre os rumos do tratamento, como a transição para cuidados paliativos, em que a presença da família ou da rede social de apoio dessas pessoas é fundamental para a promoçáo do conforto e nem sempre isso será possível, mas a enfermagem estará lá, nas 24 horas, e acabará trazendo o amparo para essas pessoas. Embora tenham tarefas assistenciais e administrativas a serem cumpridas durante o turno de trabalho, esses profissionais também precisam estar disponíveis para confortar, ouvir e apoiar os pacientes com uma atitude não apenas empática, mas também humanitária. Algumas instituiçôes e iniciativas pessoais de profissionais estáo utilizando a tecnologia como uma forma de minimizar a ausência dos familiares por meio de videochamadas, mas sabe-se que, em um país com tamanha desigualdade social como o Brasil, nem todos têm acesso a esses recursos, convocando novamente as equipes a estudarem alternativas para a necessidade de proporcionar o contato dos pacientes com seus entes queridos.

Ainda no contexto do atendimento ao paciente oncológico, cabe citar que alguns sinais e sintomas 
clássicos da Covid-19, tais como febre, diarreia, fadiga, náusea, anorexia, tontura, anosmia, disgeusia, odinofagia ${ }^{10}$ podem ser sintomas de complicaçóes do tratamento oncológico ou do próprio adoecimento por câncer, exigindo do profissional de enfermagem a elaboraçáo de uma avaliação de enfermagem baseada em evidências, para que seja identificada a doença e iniciada a terapêutica precocemente, no sentido de preservar a vida do paciente e dos demais à sua volta. Diante de tantas similaridades, a atuação na perspectiva da interdisciplinaridade e de uma comunicação mais eficaz entre as equipes torna-se mais importante do que nunca.

Outro impacto inevitável no campo da oncologia será na formação de especialistas em enfermagem oncológica e no desenvolvimento de pesquisas em oncologia de um modo geral. A pandemia de Covid-19 impôs aos oncologistas a necessidade de redefiniçấo dos protocolos de tratamento oncológico, diminuindo o número de pacientes atendidos, o que afeta diretamente na qualidade da formação dos especialistas. Essa reduçáo do número de pacientes impacta igualmente no desenvolvimento de pesquisas, especialmente nos ensaios clínicos. A disseminação das atualizaçóes e dos resultados das pesquisas consequentemente também será prejudicada, na medida em que grandes conferências mundiais estão sendo canceladas, o que pode ser devastador para o avanço no tratamento do câncer no futuro. Novamente, haverá a necessidade de estudar novos métodos de ensino e de pesquisa para minimizar as repercussóes potencialmente negativas nesses dois campos de atenção da enfermagem oncológica na era pós-Covid-19 ${ }^{11}$.

\section{CONCLUSÃO}

Considerando a divulgação praticamente diária das descobertas, atualizaçôes sobre a estrutura desse vírus, dos mecanismos de transmissibilidade, da fisiopatologia, dos tratamentos e das medidas de prevenção, de proteção e de controle, essa pandemia está nos ensinando a ir além. A enfermagem $\mathrm{e}$ as demais equipes que atuam no segmento da saúde estão sendo desafiadas a flexibilizar, a se adaptar às mudanças, a trabalhar em equipe em uma perspectiva de estreita colaboração e não de competiçấo para envidar esforços para vencer este momento de crise global inimaginável para os profissionais deste século. É de suma importância que, em prol da promoçáo da saúde e prevençáo de risco da Covid-19, unindo o binômio ciência e educação, a enfermagem oncológica possa encontrar um norte correto de fazer técnico e de reconhecimento público mundial. Conclui-se que pautar as açôes na ciência, ter paciência e usar a consciência nas açôes podem ser boas estratégias para alcançar o sucesso e sair fortalecido dessa pandemia.

\section{CONTRIBUIÇÃO}

A autora contribuiu substancialmente em todas as etapas do manuscrito e aprovou a versão final a ser publicada.

\section{DECLARAÇÃO DE CONFLITO DE INTERESSES}

Nada a declarar.

\section{FONTES DE FINANCIAMENTO}

Não há.

\section{REFERÊNCIAS}

1. Zhu N, Zhang D, Wang W, et al. A novel coronavirus from patients with pneumonia in China, 2019. N Eng J Med. 2020;382(8):727-33. doi: https://doi.org/10.1056/ NEJMoa2001017

2. World Health Organization. State of the world's nursing 2020: investing in education, jobs and leadership [Internet]. Geneva: WHO; 2020 [acesso 2020 abr 23]. Disponível em: https://www.who.int/publications-detail/ nursing-report-2020

3. Conselho Federal de Enfermagem [Internet]. Brasília, DF: Cofen; c2020 [acesso 2020 abr 22]. Enfermagem em números. Disponível em: http://www.cofen.gov.br/ enfermagem-em-numeros

4. Silva ACR, Jesus TS, Santos SS, et al. COVID-19, o novo coronavírus: um alerta emergencial para as principais estratégias de prevenção da saúde pública. Scire Salutis [Internet]. 2020 [acesso 2020 abr 21];10(2):5663. Disponível em: https://sustenere.co/index.php/ sciresalutis/article/view/4032

5. Instituto Nacional de Câncer José Alencar Gomes da Silva. Estimativa 2020 [Internet]. Rio de Janeiro: INCA; 2019 [acesso 2020 abr 21]. Disponível em: https:// www.inca.gov.br/publicacoes/livros/estimativa-2020incidencia-de-cancer-no-brasil

6. Peng L, Zagorac S, Stebbing J. Managing patients with cancer in the COVID-19 era. Eur J Cancer. 2020;132:57. doi: https://doi.org/10.1016/j.ejca.2020.03.028

7. Indini A, Aschele C, Cavanna L, et al. Reorganisation of medical oncology departments during the novel coronavirus disease-19 pandemic: a nationwide Italian survey. Eur J Cancer. 2020;132:17-23. doi: https://doi. org/10.1016/j.ejca.2020.03.024

8. Ueno LGS, Bobroff MCC, Martins JT, et al. Estresse ocupacional: estressores referidos pela equipe de enfermagem. Rev Enferm UFPE. 2017;11(4):1632-8. doi: https://doi. org/10.5205/1981-8963-v11i4a15232p1632-1638-2017

9. The Lancet Oncology. COVID-19: global consequences for oncology [Editorial]. Lancet Oncol. 2020;21(4):467. doi: https://doi.org/10.1016/S1470-2045(20)30175-3 
10. Mungroo MR, Khan NA, Siddiqui R. Novel Coronavirus: current understanding of clinical features, diagnosis, pathogenesis, and treatment options. Pathogens. 2020;9(4):297. doi: https://doi.org/10.3390/ pathogens 9040297

11. Nalley C. Navigating the COVID-19 pandemic as an oncology nurse. Oncology Times. 2020;42(8):11-18. doi: https://doi.org/10.1097/01.COT.0000661864.55789.d7

Recebido em 24/4/2020

Aprovado em 27/4/2020 